\title{
Response of barley seedlings to water deficit and enhanced UV-B irradiation acting alone and in combination
}

\author{
Hanna Bandurska • Małgorzata Pietrowska-Borek • \\ Małgorzata Cieślak
}

Received: 15 September 2010/Revised: 16 May 2011 / Accepted: 6 July 2011 / Published online: 27 July 2011

(C) The Author(s) 2011. This article is published with open access at Springerlink.com

\begin{abstract}
Responses of barley seedlings to water deficit (WD) induced by polyethylene glycol (PEG 6000) and ultraviolet (UV-B; 280-320 $\mathrm{nm}$ ) radiation and their interaction (UV-B + WD) were examined. A decrease in dry matter yield and water content of leaves and roots was observed following application of WD and UV-B + WD, while no changes were found after treating barley plants with UV-B. Proline content was increased in leaves under WD conditions and UV-B + WD. In contrast, UV-B treatment had no effect on the accumulation of proline in leaves of barley plants. Changes in root proline content showed a varied response: WD induced an increase in the level of this amino acid, while UV-B as well as UV$\mathrm{B}+\mathrm{WD}$ suppressed root proline content. The lipid peroxidation product malondialdehyde (MDA) was increased in leaves under WD and UV-B + WD stresses. Root MDA content increased in WD-stressed plants, but it decreased in the case of combined application of both stresses. The applied stress factors operated in a variable manner on phenylpropanoid metabolism. Phenylalanine ammonialyase (PAL) activity in leaves and roots was stimulated after exposure to WD and application of UV-B + WD stresses, while UV-B stress did not affect its activity. On the other hand, UV-B treatment enhanced the activity of 4:coumarate-CoA ligase (4CL) in leaves and this enhancement was positively correlated with the accumulation of anthocyanins and flavonols. However, the combined application of WD and UV-B reduced the positive
\end{abstract}

Communicated by S. Renault.

H. Bandurska $(\bowtie) \cdot$ M. Pietrowska-Borek · M. Cieślak

Department of Plant Physiology, Poznań University of Life

Sciences, Wołyńska 35, 60-637 Poznan, Poland

e-mail: bandur@up.poznan.pl effect of UV-B on the accumulation of these compounds and the activity of 4CL. Surprisingly, anthocyanins and flavonols were not detected in roots of examined barley seedlings despite increased 4CL activity. The results suggest that UV-B-induced activation of $4 \mathrm{CL}$ as well as accumulation of anthocyanin and flavonols in leaves is beneficial for the response to this stress factor. On the other hand, WD-induced reduction of the effect of UV-B on 4CL activity and the contents of anthocyanin and flavonol might be a cause of membrane damage in UV-B- and WDstressed plants. In addition, conversely to what could be expected, the UV-B effect was perceived by the waterstressed roots, which exhibited reduced lipid peroxidation (MDA) and proline accumulation in WD-stressed plants exposed to UV-B.

Keywords Flavonoids - 4:Coumarate-CoA ligase · Lipid peroxidation $\cdot$ Proline $\cdot$ Phenols .

Phenylalanine ammonia-lyase

\section{Introduction}

Water deficit (WD) and increased UV-B radiation in the total solar radiation reaching the Earth are important environmental factors limiting productivity of crops in many regions of the world (Caldwell et al. 2007; Tubiello et al. 2007; Farooq et al. 2009). Under natural field conditions WD and high UV-B irradiation operate separately, but frequently plants experience both stresses simultaneously. The co-occurrence of these stresses could alter the effect of the individual stress responses. Each of the stress factors may alleviate or increase the negative effect caused by other stresses (Mittler 2006). Plant performance under stress conditions depends on the balance between the 
harmful effect of stress factors and a wide variety of protective and repair processes (Bray 1997; Chaves et al. 2003; Caldwell et al. 2007). Like almost all environmental stresses, both WD and UV-B radiation enhance the production of active oxygen species (ROS), which may initiate destructive processes, e.g. lipid peroxidation and cell membrane damage (Smirnoff 1993; Mittler 2002). One of the most common metabolic responses to WD is the accumulation of free proline, which is believed to play many important functions in plant reactions to this stress factor (Ashraf and Foolad 2007; Szabados and Savouré 2010). This molecule is considered to provide protection against stress by acting as an ROS scavenger, as a protectant of the cell membrane and enzymes, and as an osmolyte favoring osmotic adjustment, which results in water retention and prevents dehydration (Smirnoff and Cumbes 1989; Bandurska 2000; Szegletes et al. 2000; Öztürk and Demir 2002; Kocsy et al. 2005). Transgenic plants of various species that accumulate increased amounts of proline appear to exhibit enhanced tolerance to water deficit (Kavi Kishor et al. 2005).

The effect of UV-B radiation on plants includes accumulation of phenylpropanoids, such as phenolic acids and flavonoids (Liu et al. 1995, Kozłowska et al. 2007, Zhang and Björn 2009). Phenylpropanoid compounds belong to a large family of plant secondary metabolites, which are involved in an array of processes, including plant reactions to both biotic and abiotic stresses (Winkel-Shirley 2001). These compounds are produced from trans-cinnamic acid (trans-CA), formed by deamination of L-phenylalanine in a reaction catalyzed by phenylalanine ammonia-lyase (PAL, Fig. 1; Hollósy 2002). Derivatives of trans-CA such as $p$-coumaric, ferulic and sinapic acids and their respective alcohols serve as intermediates in lignin formation (Kováčik and Klejdus 2008). Lignin deposition in cell walls increases their rigidity and contributes to both drought and UV-B resistance (Sofo et al. 2007; Yamasaki et al. 2007). Flavonoid compounds are synthesized from trans-CA in reactions catalyzed by cinnamate-4-hydroxylase $(\mathrm{C} 4 \mathrm{H})$ and 4:coumarate-CoA ligase (4CL, Fig. 1; Hollósy 2002). These compounds act as solar screens, which absorb UV-B radiation and protect plant tissue against its harmful effects (Solecka 1997; Hernández et al. 2009; Zhang and Björn 2009). Additionally, phenolic acids and flavonoids can lower generation of reactive oxygen species and prevent cellular damage (Rice-Evans et al. 1997; Gould 2004).

In this study we analyzed the impact of polyethylene glycol (PEG)-induced WD and UV-B irradiation, operating individually as well simultaneously, on some physiological and biochemical changes in barley leaves and roots. Plant responses were assessed by evaluating the leaf and root dry matter accumulation, hydration status, membrane damage and the level of proline, phenolic acids, anthocyanins and flavonols as well as the activity of PAL and 4CL.

\section{Materials and methods}

Plant material and growth conditions

Seeds of barley (Hordeum vulgare L. cv. Granal) were incubated for 7 days in a germination chamber. Seedlings of uniform size were selected and planted in pots containing Hoagland's nutrient medium, which was aerated for $3 \mathrm{~h}$ per day and $3 \mathrm{~h}$ per night. Plants were grown in a climatic chamber $\left(65-75 \%\right.$ relative humidity; $20 / 13^{\circ} \mathrm{C}$ day/ night temperatures; $14 / 10 \mathrm{~h}$ light/dark and $180 \mu \mathrm{mol} \mathrm{m}^{-2} \mathrm{~s}^{-1}$ photosynthetically active photon flux density (PPFD) provided by fluorescent Philips TLD 18 W/840 sun lamps). Two-week-old seedlings were divided into four batches subjected correspondingly to: (I) WD, (II) UV-B radiation, (III) a combination of WD and UV-B (WD + UV-B), and (IV) not treated (control).

WD and UV-B radiation treatments

Water deficit was imposed by immersing the root system in a nutrient solution containing $20 \%$ polyethylene glycol (PEG 6000). Water potential of the nutrient solution was decreased by $-0.5 \mathrm{MPa}$. Plants were irradiated with UV-B for $8 \mathrm{~h}$ a day using Philips lamps (TL $20 \mathrm{~W} / 01 \mathrm{RS}$ ) with a characteristic emission in the range of $310-320 \mathrm{~nm}$. The total energy delivered by lamps at the canopy level was $0.84 \mathrm{~W} \mathrm{~m}^{-2}$ (measured with VLX $3 \mathrm{~W}$ radiometer equipment, Vilbert Lourmant, Marne La Vallée, France). Daily dosage of UV-B radiation was $24 \mathrm{~kJ} \mathrm{~m}^{-2} \mathrm{day}^{-1}$. Control plants were grown in a nutrient solution under photosynthetically active radiation. Plant material (leaves and roots) were sampled (harvested) 10 days from the beginning of stresses imposition. Three plants per treatment were used for estimation of tissue water content and biochemical parameters. Analyses were made in three replicates derived from three different plants.

Measurements

\section{Dry matter accumulation (DM)}

DM accumulation during the experimental period was measured to estimate the effect of stresses on plant growth. Ten plants from each treatment were sampled. Shoots and roots were separated. Fresh weight of shoots and roots was measured and afterwards plant material was dried at $70^{\circ} \mathrm{C}$ to determine dry matter. Analyses were made in ten replicates derived from ten different plants. 
Fig. 1 Schematic diagram of biosynthetic pathway of flavonoid and lignin precursors

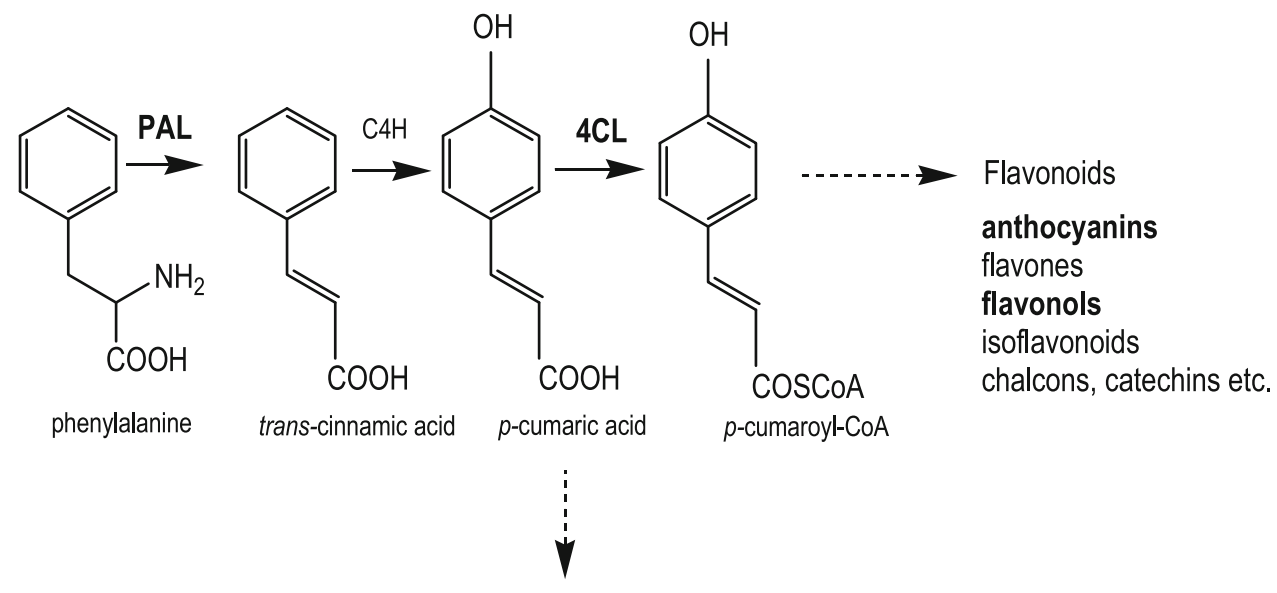

Water content in leaves was estimated by measuring relative water content (RWC) according to the standard method developed by Weatherly (1950) as described by Bandurska (2000) and it was calculated using the following formula:

RWC $=\frac{\text { fresh matter }- \text { dry matter }}{\text { fresh matter at full turgor }- \text { dry matter }} \times 100$

Fresh matter of leaves was weighed immediately after harvesting. Fresh matter of full turgor was measured after placing leaf samples in distilled water for $4 \mathrm{~h}$ under normal room light and temperature. Samples were then oven dried at $70^{\circ} \mathrm{C}$ for $24 \mathrm{~h}$ and weighed to determine dry weight.

Water content in roots (WC) was estimated by measuring fresh weight and dry weight following oven drying of fresh root samples at $70^{\circ} \mathrm{C}$. WC (\%) was calculated using the following formula:

$\mathrm{WC}=\frac{\text { fresh matter }- \text { dry matter }}{\text { fresh matter }} \times 100$

\section{Lipid peroxidation (MDA)}

Leaf and root samples $(0.3 \mathrm{~g})$ were homogenized in a chilled mortar with $3 \mathrm{~cm}^{3}$ of $0.1 \mathrm{M}$ potassium phosphate buffer $(\mathrm{pH}$ 7.0) with $30 \mathrm{mg}$ of Polyclar AT added and centrifuged at $16,000 \mathrm{~g}$ for $30 \mathrm{~min}$ at $4^{\circ} \mathrm{C}$. The level of lipid peroxidation in the supernatant was measured as the amount of malondialdehyde (MDA) determined as thiobarbituric acid (TBA) reactive substances according to Dhindsa and Matowe (1981). The volume of $2 \mathrm{~cm}^{3}$ of $20 \%$ trichloroacetic acid (TCA) containing $0.5 \%$ TBA was added to $0.5 \mathrm{~cm}^{3}$ of the supernatant. The mixture was incubated at $95^{\circ} \mathrm{C}$ for $30 \mathrm{~min}$, quickly cooled in an ice bath to room temperature and then centrifuged at $10,000 \mathrm{~g}$ for $10 \mathrm{~min}$. Absorbance of the supernatant was determined at 520 and $600 \mathrm{~nm}$. The value for nonspecific absorption at $600 \mathrm{~nm}$ was subtracted from the value at $532 \mathrm{~nm}$. The concentration of MDA was calculated using absorption coefficient of $155 \mathrm{mM}^{-1} \mathrm{~cm}^{-1}$ (Heath and Packer 1968). The level of MDA was expressed in $\mathrm{mmol} \mathrm{g}^{-1}$ of dry matter (DM).

\section{Proline content (PC)}

Leaf and root samples $(0.3 \mathrm{~g})$ were homogenized with $5 \%$ TCA. The homogenate was centrifuged at $5,000 \mathrm{~g}$ for $15 \mathrm{~min}$ and the supernatant was used for proline determination by measuring the quantity of the colored reaction product of proline with ninhydric acid according to Bates et al. (1973). Absorbance was read at $520 \mathrm{~nm}$. The PC value in the sample was calculated from the proline standard curve and expressed in $\mathrm{mg} \mathrm{g}^{-1} \mathrm{DM}$.

\section{Phenolic acid content (PAC)}

Leaf and root samples $(0.2 \mathrm{~g})$ were cut into pieces and homogenized with $5 \mathrm{~cm}^{3}$ of $80 \%$ methanol. The homogenate 
was centrifuged at $18,000 \mathrm{~g}$ for $30 \mathrm{~min}$. The Folin-Denis method was used to estimate PAC contents in the supernatant according to the method described by Swain and Hillis (1959). The level of PAC was calculated from the standard curve, using coumaric acid as a standard and expressed in $\mu \mathrm{g} \mathrm{g}^{-1} \mathrm{DM}$.

\section{Flavonol content $(F C)$}

Leaf and root samples $(0.5 \mathrm{~g})$ were cut into pieces and homogenized with $5 \mathrm{~cm}^{3}$ of methanol, $\mathrm{HCl}$ and distilled $\mathrm{H}_{2} \mathrm{O}(90: 1: 1, \mathrm{v} / \mathrm{v} / \mathrm{v})$. The solution was stirred and heated $\left(60^{\circ} \mathrm{C}\right)$ for $10 \mathrm{~min}$, cooled at room temperature for $15 \mathrm{~min}$ and centrifuged at $23,000 \mathrm{~g}$ for $30 \mathrm{~min}$ (Day 1993). The levels of flavonols were estimated by measuring absorbance of the supernatant at $254 \mathrm{~nm}$ with a UV/visible spectrophotometer (Jasco V-530 UV-VIS Spectrophotometer). FC was calculated using the calibration curves of quercetin (Stefova et al. 2001) and was expressed in $\mu \mathrm{g} \mathrm{g}^{-1}$ DM.

\section{Anthocyanin content (AC)}

Plant material was homogenized with $0.5 \mathrm{~N} \mathrm{HCl}$, and centrifuged at $23,000 \mathrm{~g}$ for $30 \mathrm{~min}$. Absorbance of the supernatant was measured at $530 \mathrm{~nm}$ using a spectrophotometer. AC was calculated using a calibration curve of cyaninchlorid according to Arakawa (1991) and it was expressed in $\mu \mathrm{g} \mathrm{g}^{-1} \mathrm{DM}$.

\section{Enzyme activity}

Phenylalanine ammonia-lyase (PAL) activity was determined using the method of Cahill and McComb (1992) according to Politycka (1999). Samples (0.5 g) were ground in a mortar at $4^{\circ} \mathrm{C}$ with $0.1 \mathrm{M}$ Tris- $\mathrm{HCl}$ buffer at $\mathrm{pH} 8.9$, containing $10 \mathrm{mmol}$ of 2-mercaptoethanol and $50 \mathrm{mg}$ of Polyclar AT. The homogenate was centrifuged at $12,000 \mathrm{~g}$ for $20 \mathrm{~min}$ at $4^{\circ} \mathrm{C}$. The reaction mixture contained $80 \mathrm{mmol}$ of borate buffer, $\mathrm{pH} 8.9,30 \mathrm{mmol}$ of L-phenylalanine and $0.5 \mathrm{~cm}^{3}$ of enzyme extract (supernatant) in a $2.5 \mathrm{~cm}^{3}$ volume. The reaction proceeded for $24 \mathrm{~h}$ at $30^{\circ} \mathrm{C}$ and was interrupted by the addition of an equal volume of $2 \mathrm{M} \mathrm{HCl}$ to the incubation mixture. The product of the reaction catalyzed by PAL-trans-cinnamic acid-was determined at $290 \mathrm{~nm}$ (Jasco-V-530 UV/VIS spectrophotometer). Enzyme activity was expressed as nkat $\mathrm{mg}^{-1}$ protein.

The assay of 4:coumarate-CoA ligase (4CL) activity was performed according to Knobloch and Hahlbrock (1977). Samples $(0.5 \mathrm{~g})$ were ground with liquid nitrogen. Frozen powder was mixed with $100 \mathrm{mM}$ Tris- $\mathrm{HCl}$ buffer at $\mathrm{pH} 7.8$ containing $5 \mathrm{mM}$ 2-mercaptoethanol and 5\% glycerol. Next $0.1 \mathrm{~g} \mathrm{~cm}^{-3}$ Dowex AG 1-X2 was added and stirred for $15 \mathrm{~min}$ at $4^{\circ} \mathrm{C}$. Extract was centrifuged at $23,000 \mathrm{~g}$ for $30 \mathrm{~min}$. The reaction mixture $\left(0.2 \mathrm{~cm}^{3}\right)$ contained $100 \mathrm{mM}$ Tris- $\mathrm{HCl}(\mathrm{pH} 7.8), 0.1 \mathrm{mM}$ coumaric acid, $0.5 \mathrm{mM}$ ATP, $0.3 \mathrm{mM} \mathrm{CoA}, 5 \mathrm{mM} \mathrm{MgCl} 2$ and $0.1 \mathrm{~cm}^{3}$ of supernatant. The activity of $4 \mathrm{CL}$ was determined spectrophotometrically at room temperature. The formation of CoA esters of coumarate acid derivatives was measured as the increase in absorbance at wavelengths of $333 \mathrm{~nm}$ according to the absorption maxima for 4-coumaroyl-CoA (Stöckigt and Zenk 1975). The molar absorption coefficient values for 4-coumaroyl-CoA $\left(21 \mathrm{mM}^{-1} \mathrm{~cm}^{-1}\right)$ were used to calculate enzyme activities. The specific enzyme activity is expressed as picokatals per milligram of total extractable protein.

Protein was determined according to the method applied by Bradford (1976), using bovine serine albumin as a standard.

Statistical analysis

ANOVA was performed to determine the significance of differences between means by Tukey's test at $P<0.05$. Statistical analyses were performed using Statistica 8.0 software.

\section{Results}

The assayed parameters of the test barley plants are influenced by the investigated stress factors. Application of WD individually and in conjunction with UV-B decreased leaf and root dry matter accumulation (Fig. 2A, B) as well as RWC in leaves and WC in roots of the test plants (Fig. 2C, D). There is no effect of UV-B treatment alone on dry matter accumulation or water content in leaves and roots of barley plants.

Membrane damage, expressed as the MDA content, was increased as compared with controls by approximately $20 \%$ in leaves of water-stressed plants and by $40 \%$ in double-stress applications (Fig. 3A). In contrast, in roots of WD-stressed plants MDA content was increased by $20 \%$ above the controls, but for the combination of WD and UV-B it decreased by $40 \%$ below the controls (Fig. 3B).

The increase in free proline content of leaves was quite pronounced for $\mathrm{WD}$, amounting to about $18 \%$ above the control value, while UV-B had almost no effect (Fig. 3C). The combination of WD and UV-B profoundly stimulated the accumulation of proline in leaves of the test plants as compared to the controls ( $40 \%$ higher than controls). In the case of roots, it was observed that WD activated the accumulation of free proline (20\% higher than controls), but for combined WD and UV-B the free proline was 
Fig. 2 Dry matter

accumulation (A, B) and water content in leaves and roots $(\mathbf{C}$, D) of barley seedlings treated with WD induced by PEG and UV-B radiation, acting individually and in combination. Different letters indicate significant differences between means of 10 replicates $(P<0.05)$

Fig. 3 Membrane damage (A, B) and proline content $(\mathbf{C}, \mathbf{D})$ in leaves and roots of barley seedlings treated with WD induced by PEG and UV-B radiation, acting individually and in combination. Different letters indicate significant differences between means of three replicates $(P<0.05)$
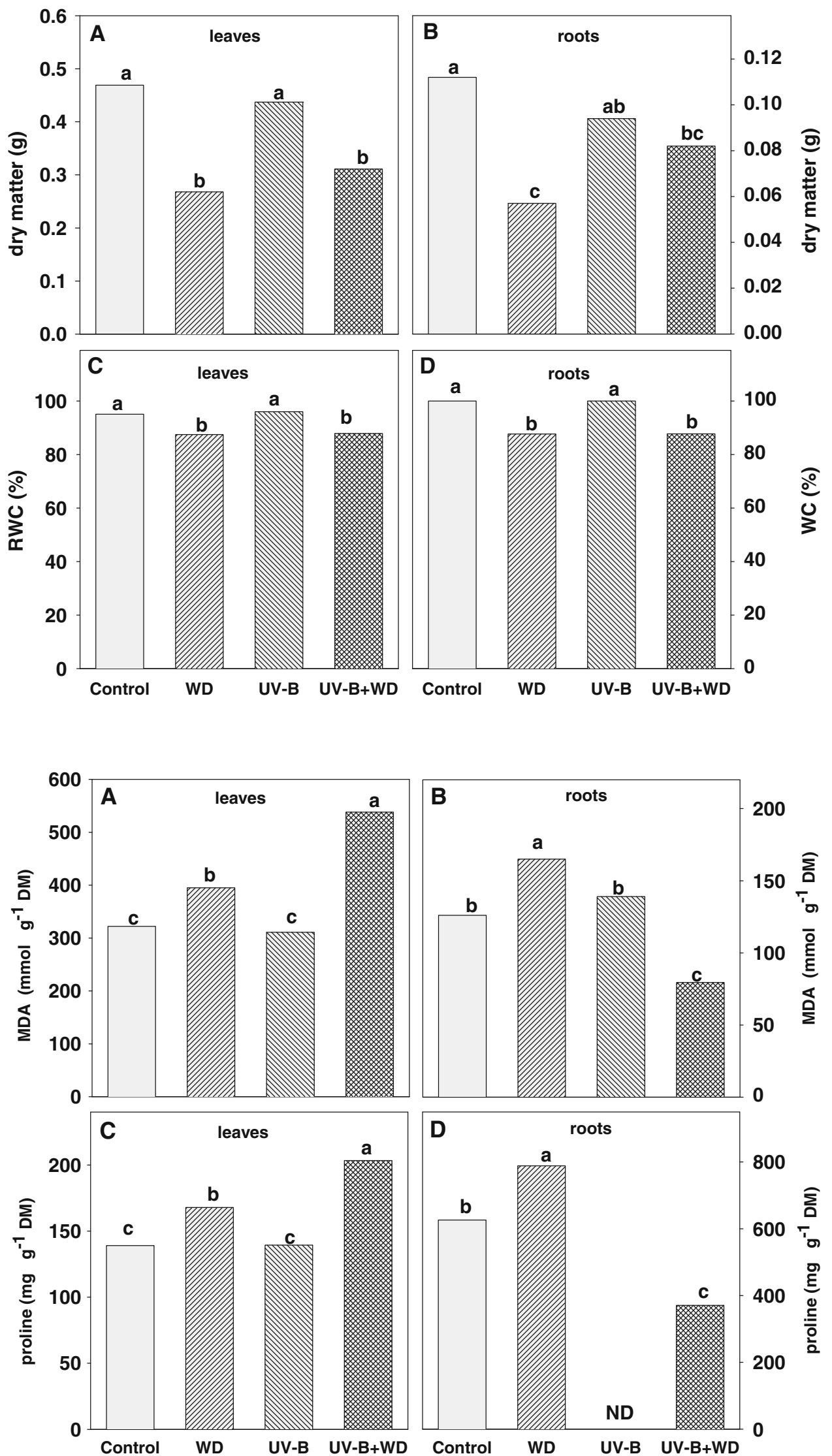
sharply reduced (50\% below controls) (Fig. 3D), while after UV-B treatment no detectable amount of proline was manifested.

The effectiveness of the applied stress factors on phenylpropanoid metabolism varied in the different organs of the test plants. In leaves of plants subjected to WD the activity of PAL was stimulated but 4CL did not change (Fig. 4A, C). UV-B radiation did not influence PAL activity, whereas it highly enhanced $4 \mathrm{CL}$ activity in leaves. When stresses were applied together, leaf PAL activity increased to the same extent as under the influence of WD alone. However, leaf 4CL activity did not change. In roots of plants subjected to WD the activity of PAL increased by about $24 \%$ over the controls, while it did not change in UV-B treated plants (Fig. 4B). Application of both stresses caused 59\% increase of root PAL activity. On the other hand, neither WD nor combined application of both stresses led to any considerable changes of 4CL activity, whereas UV-B significantly stimulated the activity of this enzyme in roots (Fig. 4D). The amounts of phenolic acids were significantly decreased in roots of test plants under WD stress. However, there were no changes in these metabolites recorded in the application of UV-B and both stresses in roots as well as in the application of all stresses in leaves (Fig. 5A, B). The level of anthocyanins was increased in leaves of WD and UV-B treated plants by about 2.5- to 4-fold that of controls, respectively (Fig. 5C).
In contrast, flavonol content was increased in leaves of UVB treated plants by about $38 \%$ over the control value (Fig. 5D). There were no changes in leaf flavonol content of WD and WD + UV-B treated plants. Surprisingly, anthocyanins and flavonols were not detected in roots of examined barley seedlings.

\section{Discussion}

The negative effects of WD (PEG $-0.5 \mathrm{MPa}$ ) on dry matter accumulation as well as tissue water content and the absence of changes in these parameters in UV-B $\left(24 \mathrm{~kJ} \mathrm{~m}^{-2} \mathrm{day}^{-1}\right)$ treated plants indicate that the reaction of barley seedlings to the applied stress factors was heterogeneous. In the experiment on black mustard (Brassica nigra) and turnip (Brassica rapa) both moderate soil WD (drought) and UV-B radiation at the levels of 6 and $17 \mathrm{~kJ} \mathrm{~m}^{-2}$ day $^{-1}$ had detrimental effects on plant growth indices, but the effect of WD was much stronger than that of UV-B (Conner and Zangori 1998). A stronger effect of severe WD (PEG $-2.0 \mathrm{MPa}$ ) than that of UV-B $\left(13.6 \mathrm{~kJ} \mathrm{~m}^{-2} \mathrm{day}^{-1}\right)$ on dry matter of aboveground parts was found in soy (Glycine max) (Sullivan and Teramura 1990). Conversely, a higher dose of UV-B $\left(49 \mathrm{~kJ} \mathrm{~m}^{-2}\right.$ $\mathrm{day}^{-1}$ ) caused a stronger effect than moderate WD (PEG $0.5 \mathrm{MPa})$ on pea and wheat dry matter accumulation
Fig. 4 Activity of phenylalanine ammonia-lyase $(\mathbf{A}, \mathbf{B})$ and 4:coumarate-CoA ligase $(\mathbf{C}, \mathbf{D})$ in leaves and roots of barley seedlings treated with WD induced by PEG and UV-B radiation, acting individually and in combination. Different letters indicate significant differences between means of three replicates $(P<0.05)$
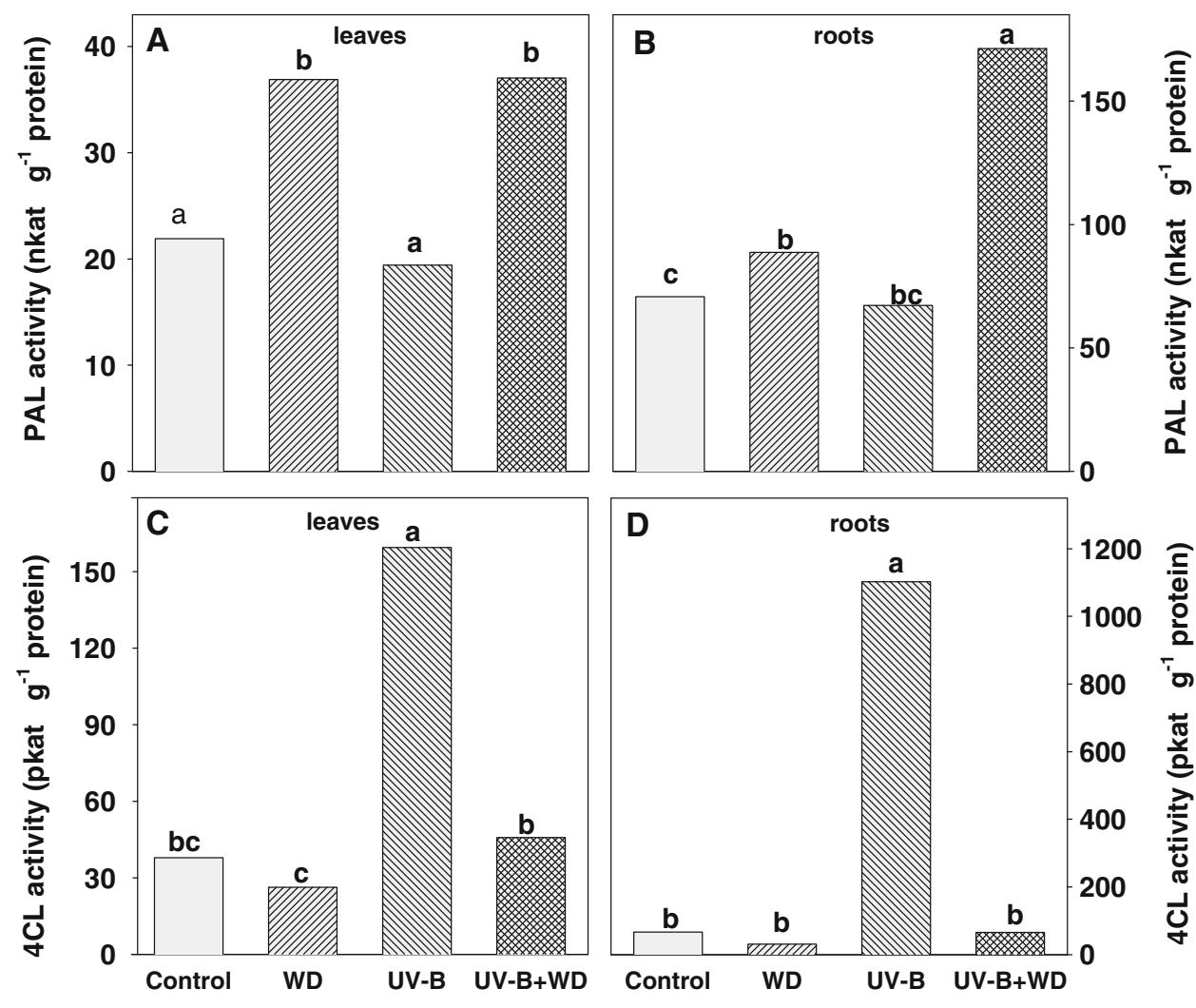
Fig. 5 Soluble phenol levels in leaves and roots $(\mathbf{A}, \mathbf{B})$, anthocyanin $(\mathbf{C})$ and flavonol (D) levels in leaves of barley seedlings treated with WD induced by PEG and UV-B radiation, acting individually and in combination. Different letters indicate significant differences between means of three replicates $(P<0.05)$
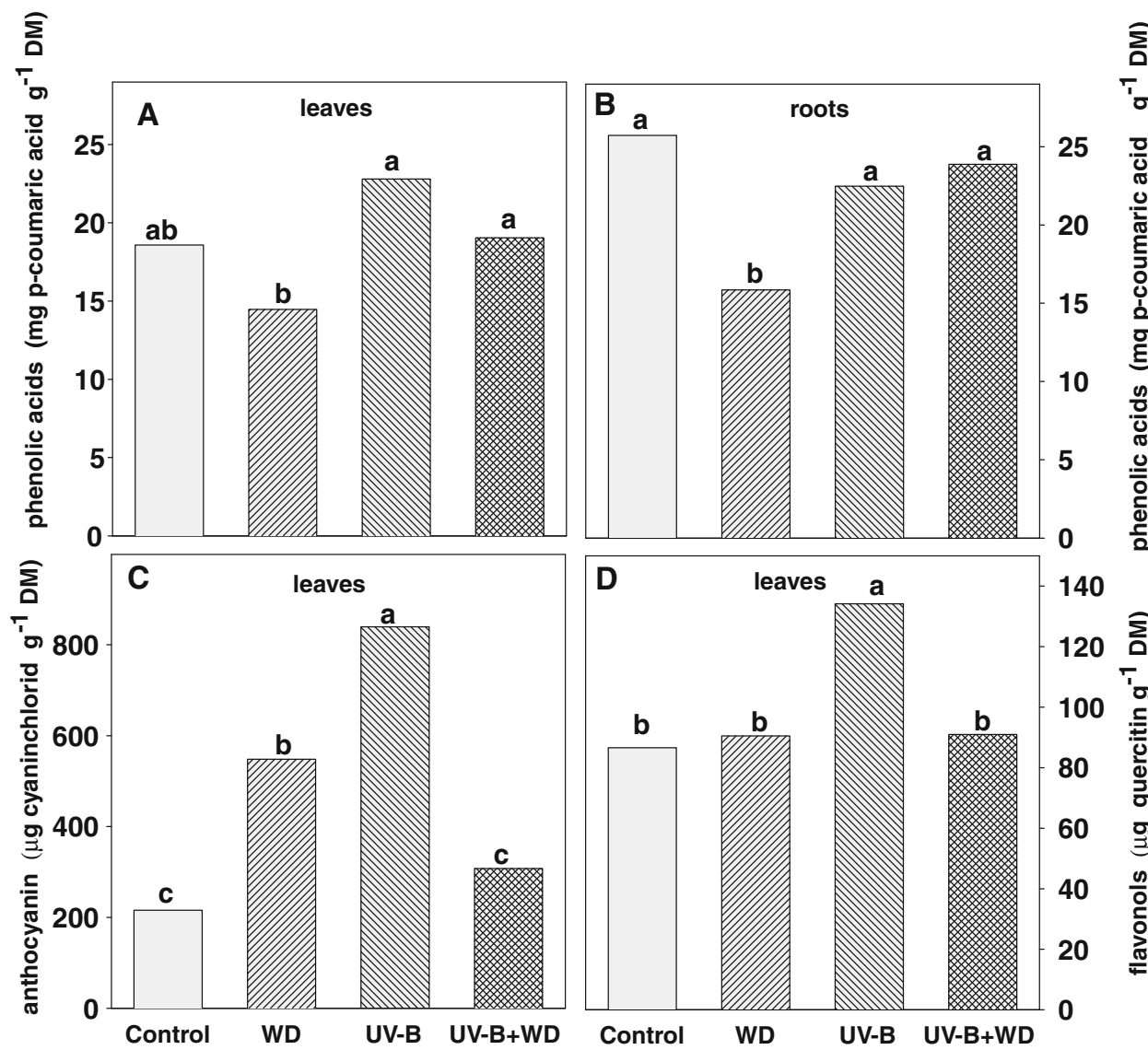

(Alexieva et al. 2001). The effect of combined action of WD and UV-B radiation on growth parameters in the test barley plants was generally similar to the effect caused by WD only. However, in wheat the combination of WD (PEG -0.5 MPa) with UV-B $\left(3.5 \mathrm{~kJ} \mathrm{~m}^{-2}\right.$ day $\left.^{-1}\right)$ caused more severe reduction of fresh matter of aboveground parts than stress factors applied separately (Tian and Lei 2007).

Inhibition of plant growth under water deficit conditions is a consequence of reduced cell turgor (Spollen et al. 1993). The results of this study indicate that a moderate WD contributed only slightly to changes in leaf hydration, while causing rather high growth inhibition in these organs. A significant factor in the mechanism of cell enlargement is cell wall extensibility (Cosgrove 1993; Passioura 1994). Under water deficit conditions cell wall extensibility may be reduced due to the formation of cross-linking between polymers forming them as well as deposition of lignins (Bacon et al. 1997; Lee et al. 2007; Moura et al. 2010). The biosynthesis of lignin and cross-linking formation of primary cell walls occur through a sequence of reactions, in which phenolic acids are involved (Fry 1986). The first stage in the formation of phenolic acids is deamination of phenylalanine catalyzed by PAL (Whetten et al. 1998). In the present study the action of WD and combined action of both factors contributed to increased PAL activity in leaves and in roots, which was accompanied by growth inhibition in these organs. In turn, an increase in PAL activity together with a lack of changes or a reduction of phenolic acid levels, which was observed in this study, indirectly indicates their consumption in metabolic processes responsible for lignification of cell walls under WD conditions. In our earlier studies we showed that WD contributed to lignification of cell walls in both leaves and roots of barley (Bandurska et al. 2005). Recently Fan et al. (2006) shown that WD induced by PEG initiated alterations in accumulation and metabolism of wall-linked phenolic substances, which are involved in inhibition of wall extensibility and root growth.

A slight reduction of water content in barley leaves under the influence of WD deficit may indicate a rapid closure of stomata. A significant role in this respect is played by abscisic acid (Chaves et al. 2003). This is confirmed by the results of our previous investigations, in which we observed a rapid increase of ABA level under the influence of WD in roots and next in leaves of barley, which was correlated with a high RWC level in leaves (Bandurska and Stroiński 2003). However, closure of stomata may lead to a reduced intensity of photosynthesis and, as a consequence, growth inhibition (Farooq et al. 2009). Another effect of stomatal closure, causing a reduction of 
carbon dioxide assimilation at an unchanged level of absorption of light energy by the photosynthesizing organ, is an increase in the level of reactive oxygen species (ROS) in cells and damage to cell structures through lipid peroxidation (Syros et al. 2004; Miller et al. 2010). Several studies also showed that enhanced UV-B radiation caused generation of ROS and an increase of lipid peroxidation in many plants (Fedina et al. 2003; Feng et al. 2007; Tian and Lei 2007). In the present study only WD caused an increase in MDA level in leaves and roots of barley. Similarly, in leaves of beans, mulberry and wheat, as well as in leaves and roots of cucumber, the action of WD resulted in an increase in lipid peroxidation (Sairam et al. 1997; Reddy et al. 2004; Türkan et al. 2005, Arasimowicz-Jelonek et al. 2009a, b). Tian and Lei (2007) reported that the individual action of WD and UV-B radiation induced an increase in leaf MDA level in wheat. In turn, the simultaneous action of both factors resulted in their synergistic effect on the increase in MDA level. A similar reaction was also observed in our study in barley leaves, where the simultaneous application of WD and UV-B had a stronger effect on increased MDA level than single action. However, in barley roots the simultaneous action of both factors was antagonistic in character.

Accumulation of free proline is a characteristic and well-documented reaction of plants to the action of water deficit (Verbrugen and Hermans 2008). Under the influence of UV-B a slight increase in the level of this amino acid was found in leaves of pea, wheat and white clover (Trifolium repens) populations, while a lack of changes was observed in leaves of wheat (Alexieva et al. 2001; Hoffmann et al. 2003; Tian and Lei 2007). Moreover, in wheat seedlings combined application of both stresses had a stronger (synergistic) effect on proline accumulation than stress factors applied separately (Tian and Lei 2007). In the present study a mild WD contributed to an increase in the level of this amino acid both in leaves and roots, which is consistent with our earlier investigations (Bandurska et al. 2005). In contrast, we observed a lack of effect of UV-B on the accumulation of free proline in barley leaves. However, simultaneous action of WD and UV-B had a synergistic effect on leaf proline accumulation. The negative and antagonistic effect of UV-B radiation on proline level in roots-in contrast to WD-came as a surprise.

There is some evidence that plants exposed to UV-B accumulate proline, which can protect plants against lipid peroxidation induced by UV-B light (Saradhi et al. 1995; Alia et al. 1997). The results of this study do not confirm such an effect of UV-B radiation on the accumulation of proline and lipid peroxidation. Under WD conditions and the simultaneous action of both stressors, leaf proline accumulation was accompanied by an increase in the level of lipid peroxidation. However, in our opinion this may not be evidence for the protective role of proline. This is because the increase in the level of lipid peroxidation is a consequence of damage to cell membranes. It was demonstrated by other authors that an exogenous application of proline did not have a protective effect against UV-Binduced increase in lipid peroxidation (Fedina et al. 2003).

Several studies have suggested that flavonoid pigments exert a protective function against UV-B-induced damage because of their antioxidant capacity (Middleton and Teramura 1993; Bharti and Khurana 1997; Hernández et al. 2008). In our study this is indicated by a considerable increase in leaf anthocyanin and flavonol levels under the influence of UV-B radiation and a lack of peroxidation damage in cell membranes, as well as a lack of a negative effect of this factor on biomass accumulation. PAL activity is a key factor responsible for increased accumulation of flavonoids and other phenolic compounds in barley leaves under UV-B radiation (Liu et al. 1995). It has been reported that PAL activity positively correlated with anthocyanin synthesis in fruit of grapes, strawberries and apple (Horbowicz et al. 2008). Other authors have demonstrated that when apples ripen, anthocyanin accumulation decreases, even though PAL activity is relatively high (Wang et al. 2000). Our results show that UV-B radiation enhanced the production of anthocyanins and flavonols. However, no effect of UV-B radiation on PAL activity was found. It seems that the enhanced production of anthocyanins and flavonols induced by UV-B was due to increased activity of 4CL. This enzyme catalyzes activation reactions of derivatives of cinnamic acid, which are transformed into respective thiol esters of coenzyme $\mathrm{A}$, constituting precursors for the synthesis of different secondary metabolites (Dixon and Palva 1995). The UV-B induced de novo synthesis of 4CL ligase and the accumulation of flavonoids were demonstrated in cell suspension cultures of parsley (Kuhn et al. 1984). In leaves of Arabidopsis thaliana a 30\% increase was observed in the expression of 4CL genes under the influence of UV-B radiation (Kimura et al. 2003). Arabidopsis mutants with a defect of synthesis of flavonoid compounds were sensitive to UV-B radiation and, on the other hand, mutants with elevated accumulation of these compounds were tolerant to this stress factor ( $\mathrm{Li}$ et al. 1993; Bieza and Lois 2001). Similarly, UV-B screening capacity and a lower degree of damage in barley primary leaves were mainly due to UV-B induced flavonoid accumulation (Schmitz-Hoerner and Weissenböck 2003). Moreover, Middleton and Teramura (1993) demonstrated the photoprotective function of flavonoids in UV-B treated soybean plants. A pronounced increase in the level of UV$\mathrm{B}$ absorbing compounds and a greater tolerance to UV-B as well as to drought were observed in poplar species originating from high altitudes than those originating from lower altitudes (Ren et al. 2007). 
At the lack of coenzyme A, 4:coumarate-CoA ligase may catalyze the synthesis of nucleotides such as adenosine- $5^{\prime}$-tetraphosphate and diadenosine tetraphosphate, whose functions in plants have not been clarified to date (Pietrowska-Borek et al. 2003). It could have occurred in the roots of barley plants treated with UV-B radiation in this study, where a considerable increase was observed in the activity of $4 \mathrm{CL}$ and a lack of that of anthocyanins and flavonols.

In leaves of pea plants both WD and UV-B increased anthocyanin contents when imposed alone and had a synergistic effect when imposed together (Nogués et al. 1998). Our results also showed that WD treatment caused a considerable increase in the level of leaf anthocyanins, which correlated with PAL activity. In turn, under the influence of the combined action of both stress factors, despite increased PAL activity, the content of anthocyanins did not change. Moreover, a lack of effect was found for WD and the simultaneous action of WD and UV-B radiation on 4CL activity.

From our results it appears that the activation of $4 \mathrm{CL}$ as well as accumulation of anthocyanin and flavonols in leaves provoked by UV-B seems to be beneficial for the response to this stress factor. On the other hand, WDinduced reduction in the effect of UV-B on 4CL activity as well as anthocyanin and flavonol contents seems to be a cause of membrane damage in UV-B- and WD-stressed plants. However, conversely to what could be expected, the UV-B effect was perceived by the water-stressed roots. It was exhibited by reduced lipid peroxidation (MDA) and reduced proline accumulation in roots of WD-stressed plants exposed to UV-B.

Open Access This article is distributed under the terms of the Creative Commons Attribution Noncommercial License which permits any noncommercial use, distribution, and reproduction in any medium, provided the original author(s) and source are credited.

\section{References}

Alexieva V, Sergiev I, Mapelli S, Karanov E (2001) The effect of drought and ultraviolet radiation on growth and stress markers in pea and wheat. Plant Cell Environ 24:1334-1344

Alia, Saradhi PP, Mohanty P (1997) Involvement of proline in protecting thylakoid membranes against free radical-induced photodamage. J Photochem Photobiol B: Biol 38:253-257

Arakawa O (1991) Effect of temperature on anthocyanin accumulation in apple fruit as affected by cultivar, stage of fruit ripening and bagging. J Hort Sci 66:763-768

Arasimowicz-Jelonek M, Floryszak-Wieczorek J, Kubiś J (2009a) Interaction between polyamine and nitric oxide signaling in adaptive responses to drought in cucumber. J Plant Growth Regul 28:177-186

Arasimowicz-Jelonek M, Floryszak-Wieczorek J, Kubiś J (2009b) Involvement of nitric oxide in water stress-induced responses of cucumber roots. Plant Sci 177:682-690
Ashraf M, Foolad MR (2007) Roles of glycine betaine and proline in improving plant biotic stress resistance. Environ Exp Bot 59: 206-216

Bacon MA, Thompson DS, Davies WJ (1997) Can cell wall peroxidase activity explain the leaf growth response of Lolium temulentum L. during drought? J Exp Bot 48:2075-2085

Bandurska H (2000) Does proline accumulated in leaves of water deficit stressed barley plants confine cell membrane injury? I. Free proline accumulation and membrane injury index in drought and osmotically stressed plants. Acta Physiol Plant 22:409-415

Bandurska H, Stroiński A (2003) ABA and proline accumulation in leaves and roots of wild (Hordeum spontaneum) and cultivated (Hordeum vulgare 'Maresi') barley genotypes under water deficit conditions. Acta Physiol Plant 25:55-61

Bandurska H, Politycka B, Stroiński A, Zielezińska M (2005) The effect of water deficit, $\mathrm{ABA}$ and JA on the activity of phenylalanine ammonia-lyase and the level of lignin and salicylic acid in barley. Acta Physiol Plantarum 27:17

Bates LS, Waldren RP, Teare JD (1973) Rapid determination of proline for water stress studies. Plant Soil 39:205-207

Bharti AK, Khurana JP (1997) Mutants of Arabidopsis as tools to understand the regulation of phenylpropanoid pathway and UVB protection mechanisms. Phytochem Photobiol 65:765-776

Bieza K, Lois R (2001) An Arabidopsis mutant tolerant to lethal ultraviolet-B levels shows constitutively elevated accumulation of flavonoids and other phenolics. Plant Physiol 126:1105-1115

Bradford MM (1976) A rapid and sensitive method for the quantitation of microgram quantities of protein utilizing the principle of protein-dye binding. Anal Biochem 72:248-254

Bray E (1997) Plant responses to water deficit. Trends Plant Sci 2:48-54

Cahil DM, McComb JA (1992) A comparison of changes in phenylalanine ammonia-lyase activity, lignin and phenolic synthesis in the roots of Eucalyptus calophylla (field resistant) and E. marginata (susceptible) when infected to Phytophtora cinnamoni. Physiol Mol Plant Pathol 40:315-332

Caldwell MM, Bornmam JF, Ballaré CL, Fint SD, Kulandavelu G (2007) Terrestrial ecosystems, increased solar ultraviolet radiation, and interactions with other climate changes factors. Photochem Photobiol 6:252-266

Chaves MM, Maroco JP, Pereira J (2003) Understanding plant responses to drought-from genes to the whole plant. Funct Plant Biol 30:239-264

Conner JK, Zangori LA (1998) Combined effects of water, nutrient, and UV-B stress on female fitness in Brassica (Brassicae). Am J Bot 85:925-930

Cosgrove DJ (1993) How do plant cell walls extend ? Plant Physiol 102:1-6

Day TA (1993) Relating UV-B radiation screening effectiveness of foliage to absorbing-compound concentration and anatomical characteristics in a diverse group of plants. Oecologia 95: $542-550$

Dhindsa R, Matowe W (1981) Drought tolerance in two mosses: correlated with enzymatic defense against lipid peroxidation. J Exp Bot 32:79-91

Dixon AR, Palva NL (1995) Stress-induced phenylpropanoid metabolism. Plant Cell 7:1085-1097

Fan L, Linker R, Gepstein S, Tanimoto E, Yamamoto R, Neuman PM (2006) Progressive inhibition by water deficit of cell wall extensibility and growth along the elongation zone of maize roots is related to increased lignin metabolism and progressive stellar accumulation of wall phenolics. Plant Physiol 140:603-612

Farooq M, Wahid A, Kobayashi N, Basra SMA (2009) Plant drought stress: effects, mechanisms and management. Agron Sustain Dev 29:185-212 
Fedina IS, Georgieva K, Georgieva I (2003) Response of barley seedlings to UV-B radiation as affected by proline and $\mathrm{NaCl}$. Bil Plant 47:549-554

Feng H, Li S, Xue L, An L, Wang X (2007) The interactive effects of enhanced UV-B radiation and soil drought on spring wheat. South Afr J Bot 73:429-434

Fry SC (1986) Cross-linking of matrix polymers in the growing cell wall of angiosperms. Ann Rev Plant Physiol 37:165-186

Gould KS (2004) Nature's swiss army knife: The diverse protective roles of anthocyanins in leaves. J Biomed Biotechnol 5:314-320

Heath RL, Packer L (1968) Effect of light on lipid peroxidation in chloroplasts. Biochem Biophys Res Comm 19:716-720

Hernández I, Alegre L, Van Breugsegem F, Munné-Bosch S (2009) How relevant are flavonoids as antioxidants in plants? Trends Plant Sci 4:125-132

Hoffmann RW, Campbell BD, Bloor SJ, Swinny EE, Markham KR, Ryan KG, Fountain DW (2003) Responses to UV-B radiation in Trifolium repens L.-physiological links to plant productivity and water availability. Plant Cell Environ 26:603-612

Hollósy F (2002) Effects of ultraviolet radiation on plant cells. Micron 33:179-197

Horbowicz M, Grzesiuk A, Dębski H, Koczkodaj D, Saniewski M (2008) Methyl jasmonate inhibits anthocyanin synthesis in seedlings of common buckwheat (Fagopyrum esculentum Moench). Acta Biol Cracoviensia Series Bot 50:71-78

Kavi Kishor PB, Sangam S, Amrutha RN, Sri Laxmi P, Naidu KR, Rao KRSS, Rao S, Reddy KJ, Theriappan P, Sreenivasulu N (2005) Regulation of proline biosynthesis, degradation, uptake and transport in higher plants: Its implications in plants growth and abiotic stress tolerance. Curr Sci 88:424-438

Kimura T, Yamamato YY, Seki M, Sakurai T, Sato M, Abe T, Yoshida S, Manabe K, Matsui M (2003) Identification of Arabidopsis genes regulated by high light-stress using cDNA microarray. Phytochem Photobiol 77:226-233

Knobloch KH, Hahlbrock K (1977) 4-Coumarate:CoA ligase from cell suspension of Petroselinum hortense Hoffm. Partial purification, substrate specificity, and further properties. Arch Biochem Biophys 184:237-248

Kocsy G, Laurie R, Szalai G, Szilgyi V, Simon-Sarkadi L, Galiba G, Ronde JA (2005) Genetic manipulation of proline levels affects antioxidants in soybean subjected to simultaneous drought and heat stresses. Physiol Plant 124:227-235

Kováčik J, Klejdus B (2008) Dynamics of phenolic acids and lignin accumulation in metal-treated Matricaria chamomilla roots. Plant Cell Rep 27:605-615

Kozłowska M, Brzezińska E, Stobiecki M (2007) Sensitivity differences and accumulation of screening compounds in three conifer plants under enhanced UV-B radiation. Polish J Environ Stud $16: 823-830$

Kuhn DN, Chappell J, Boudet A, Hahlbrock K (1984) Induction pf phenylalanine ammonia-lyase and 4-coumarate: CoA ligase mRNAs in cultured plant cells by UV light or fungal elicitors. Proc Natl Acad Sci 81:1102-1106

Lee B-R, Kim K-Y, Jung W-J, J-Ch Avice, Ourry A, Kim T-H (2007) Peroxidases and lignification in relation to the intensity of waterdeficit stress in white clover (Trifolium repens L.). J Exp Bot 58:1271-1279

Li J, Ou-Lee T-M, Raba R, Amundson RG, Last RL (1993) Arabidopsis flavonoid mutants are hypersensitive to UV-B irradiation. Plant Cell 5:171-179

Liu L, Gitz DC, McClure JW (1995) Effects of UV-B on flavonoids, ferulic acid, growth and photosynthesis in barley primary leaves. Physiol Plant 93:725-733

Middleton EM, Teramura AH (1993) The role of flavonol glycosides and carotenoids in protecting soybean from ultraviolet-B damage. Plant Physiol 103:741-752
Miller G, Suzuki N, Ciftici-Yilmaz S, Mittler R (2010) Reactive oxygen species homeostasis and signalling during drought and salinity stresses. Plant Cell Environ 33:453-467

Mittler R (2002) Oxidative stress, antioxidants and stress tolerance. Trends Plant Sci 7:405-410

Mittler R (2006) Abiotic stress, the field environment and stress combination. Trends Plant Sci 11:15-19

Moura JCMS, Bonine CAV, Viana JOF, Dornelas MC, Mazzafera P (2010) Abiotic and biotic stresses and changes in the lignin content and composition in plants. $\mathrm{J}$ Integr Plant Biol $52: 360-376$

Nogués S, Allen DJ, Morison JJL, Baker NR (1998) Ultraviolet-B radiation effects on water relations, leaf development, and photosynthesis in droughted pea plants. Plant Physiol 117: 173-181

Öztürk L, Demir Y (2002) In vivo and in vitro protective role of proline. Plant Growth Regul 38:259-264

Passioura JB (1994) The physical chemistry of the primary cell wall: implications for the control of expansion rate. J Exp Bot 45:1675-1682

Pietrowska-Borek M, Stuible HP, Kombrink E, Guranowski A (2003) 4-Coumarate: coenzyme A ligase has the catalytic capacity to synthesize and reuse various (Di) adenosine polyphosphatase. Plant Physiol 131:1401-1403

Politycka B (1999) Ethylene-dependent activity of phenylalanine ammonia-lyase and lignin formation in cucumber roots exposed to phenolic allelochemicals. Acta Soc Bot Pol 68:123-127

Reddy AR, Chaitanya KV, Jutur PP, Sumithra K (2004) Differential antioxidant responses to water stress among five mulberry (Morus alba L.) cultivars. Environ Exp Bot 52:33-42

Ren J, Dai W, Xuan Z, Yao Y (2007) The effect of drought and enhanced UV-B radiation on the growth and physiological traits of two contrasting poplar species. Forest Ecol Man 239:112-119

Rice-Evans CA, Miller NJ, Paganga G (1997) Antioxidant properties of phenolic compounds. Trends Plant Sci 2:152-159

Sairam RK, Shukla DS, Saxena DC (1997) Stress induced injury and antioxidant enzymes in relation to drought tolerance in wheat genotypes. Biol Plant 40:357-364

Saradhi PP, Alia, Arora S, Prasad KV (1995) Proline accumulates in plants exposed to UV radiation and protects them against UV induced peroxidation. Biochem Biophys Res Commun 1:1-5

Schmitz-Hoerner R, Weissenböck G (2003) Contribution of phenolic compounds to the UV-B screening capacity of developing barley primary leaves in relation to DNA damage and repair under elevated UV-B levels. Phytochem 64:243-255

Smirnoff N (1993) The role of active oxygen in the response of plants to water deficit and desiccation. New Phytol 125:27-58

Smirnoff N, Cumbes QJ (1989) Hydroxyl radical scavenging activity of compatible solutes. Phytochemistry 28:1057-1060

Sofo A, Manfreda S, Dichio B, Fiorentino M, Xiloyannis C (2007) The olive tree: a paradigm for drought tolerance in Mediterranean climates. Hydrol Earth Syst Sci Discuss 4:2811-2835

Solecka D (1997) Role of phenylpropanoid compounds in plant responses to different stress factors. Acta Physiol Plant 19: 257-268

Spollen WG, Sharp RE, Saab IN, Wu Y (1993) Regulation of cell expansion in roots and shoots at low water potentials. In: Smith JAC, Griffiths (eds) Water deficits. Plant responses from cell to community, Oxford BIOS Scientific Publishers, pp 37-52

Stefova M, Kulevanova S, Stafilov T (2001) Assay of flavonols and quantification of quercetin in medicinal plants by HPLC with UV-diode array detection. J Liq Chrom Rel Technol 24: 2283-2292

Stöckigt J, Zenk MH (1975) Chemical syntheses and properties of hydroxycinnamoyl-coenzyme A derivatives. Z Naturforsch 30c: $352-358$ 
Sullivan JH, Teramura AH (1990) Field study of the interaction between solar ultraviolet-B radiation and drought on photosynthesis and growth in soybean. Plant Physiol 92:141-146

Swain J, Hillis WE (1959) The phenolic constituents of Prumus domestical. The quantitative analysis of phenolic constituents. J Sci Food Agric 10:63-68

Syros T, Yupsanis T, Omirou M, Economou A (2004) Photosynthetic response and peroxidase in relation to water and nutrient deficiency in gerbera. Environ Exp Bot 52:23-31

Szabados L, Savouré A (2010) Proline: multifunctional amino acid. Trends in Plant Sci 15:89-97

Szegletes Z, Erdei L, Tari I, Cseuz L (2000) Accumulation of osmoprotectants in wheat cultivars of different drought tolerance. Cereal Res Commun 28:403-410

Tian XR, Lei YB (2007) Physiological responses of wheat seedlings to drought and UV-B radiation. Effect of exogenous sodium nitroprusside application. Russ J Plant Physiol 54:676-682

Tubiello N, Sousana JE, Howden SM (2007) Crop and pasture response to climatic change. Proc Nat Acad Sci 104:19686-19690

Türkan I, Bor M, Özdemir F, Koca H (2005) Differential responses of lipid peroxidation and antioxidants in the leaves of droughttolerant $P$. acutifolius Gray and drought-sensitive $P$. vulgaris $\mathrm{L}$. subjected to polyethylene glycol mediated water stress. Plant Sci 168:223-231
Verbrugen N, Hermans CH (2008) Proline accumulation in plants: a review. Amino acids 35:753-759

Wang H, Arakawa O, Motomura Y (2000) Influence of maturity and bagging on relationship between anthocyanin accumulation and phenylalanine ammonia-lyase (PAL) activity in 'Jonathan' apples. Postharv Biol Techn 19:123-128

Weatherly PE (1950) Studies in water relation of cotton plants. I. The measurement of water deficits in leaves. New Phytol 49:81-97

Whetten RW, MacKay JJ, Sederoff RR (1998) Recent advantages in understanding lignin biosynthesis. Ann Rev Plant Physiol Plant Mo Biol 49:585-609

Winkel-Shirley B (2001) It takes a garden. How work on diverse plant species has contributed to an understanding of flavonoid metabolism. Plant Physiol 127:1399-1404

Yamasaki S, Noguchi N, Mimaki K (2007) Continuous UV-B irradiation indices morphological changes and the accumulation of polyphenolic compounds on the surface of cucumber cotyledons. J Radiat Res 48:443-454

Zhang WJ, Björn LO (2009) The effect of ultraviolet radiation on the accumulation of medical compounds in plants. Fitoterapia 80:207-218 